\title{
Mapping Interactional Organisation in CLIL Classrooms: Saudi Tertiary Level
}

\author{
Sabria S. Jawhar, PhD \\ Assistant professor of Applied and Educational Linguistics \\ Languages and Cultural Studies Department \\ King Saud bin Abdulaziz University for Health Sciences \\ Kingdom of Saudi Arabia \\ Haifa A. Alnofaie, PhD \\ Assistant professor of Applied and Educational Linguistics \\ Department of Foreign Languages/ College of Art \\ Taif University, Kingdom of Saudi Arabia
}

\begin{abstract}
This article uses a conversation analysis (CA) methodology to investigate classroom interaction in Content and Language Integrated Learning (CLIL) classrooms in Saudi higher education. Most of the work that has examined classroom interaction in CLIL has used various frameworks, such as an interactional framework and/ or a discoursepragmatic framework. There is still lack of research that explores the micro details of talk-in-interaction in CLIL contexts using CA, particularly in higher education. Based on a corpus of 16 tertiary education CLIL lessons, this article provides an account of the interactional organisation of Saudi higher education CLIL classrooms. It also provides an in-depth investigation of the ways in which Saudi students display orientation to knowledge within this instructional setting.
\end{abstract}

Keywords: CLIL, classroom interaction, higher education, conversation analysis.

\section{INTRODUCTION}

Following the paradigm shift that resulted from the publication of Firth and Wagner's (1997) paper in which they argued for the importance of the social and interactional aspects of language learning, classroom interaction has become the core of SLA research (Kasper, 1997; Liddicoat, 1997; Rampton, 1997). However, interaction in CLIL is still under-researched, particularly from a conversation analysis perspective. Most of the studies that have examined this context were conducted using discourse-pragmatic perspective (Nikula 2002, 2005, 2007; Dalton-Puffer, 2005; Dalton-Puffer \& Nikula, 2006). These studies provided a detailed picture of the use of language in CLIL; however, they were mainly focused on the use of various directive speech acts and language patterns used by teachers and students. Other studies investigated CLIL using an interactional perspective, with special attention being paid to how language and content could potentially be interwoven via the participants' interactive practices. In these research studies, the focus was mainly on describing how the teachers' different teaching strategies contributed to creating more participation opportunities for the learners (Hall \& Verplaetse, 2000). Pehkonen (2008) also studied CLIL classroom interaction, focusing on the teachers' evaluative turns and how they were constructed, thus providing an insight into the intricate interactional practices of CLIL teachers. Overall, the literature review shows that studies that investigate CLIL by employing a CA framework remain scarce. The few recent studies that have examined CLIL using CA, such as the study by Morton (2015), have 
mainly focused on specific aspects of CLIL interaction such as explanations of vocabulary. This study is an addition to the body of research that looks deeply into interaction in CLIL higher education, thus reflecting the overall "architecture of interaction" (Seedhouse, 2004). It presents an investigation of the micro processes entailed in classroom interaction. It sheds light on the ways in which teachers and students organise and construct taking turns, address breakdowns in communication and project repair on the sequential action-by-action level.

\section{METHODOLOGICAL FRAMEWORK}

In this paper, we use CA as the main method for analysis. CA owes its existence to the early work of Harvey Sacks and his collaborators, including Emanuel Schegloff and Gail Jefferson. Although CA was developed in 1960s, Harold Garfinkel was the main author behind the idea of CA as a tool for social science analysis.

CA can be defined as a micro-analytical, detailed way of studying naturally occurring conversation in order to obtain a better understanding of the local aspects of interaction. It also examines ways in which participants take turns and constructs sequences of utterances in a conversation. The way in which participants identify and repair emerging problems in the conversation is also an extremely important aspect of CA (Hopper et al., 1986; Pomerantz \& Fehr, 1997).

The sequential analysis of the interaction is a core factor in the way CA approaches any data because it assumes that social actions take place in sequences of turns-at-talk. Nevertheless, these actions only derive their meanings from the particular position within the sequences in which they are placed. Heritage (1995) referred to this placement of sequences as the "architecture of intersubjectivity".

Intersubjectivity is understood as the participants' understanding of their own states of knowledge, as well as their intention towards and relationship to each other. It can be examined at the basic level of turn taking in which the participants co-construct their turns based on their understanding of the preceding turn (Sacks et al., 1974). It can also be scrutinised at the context level, which is more relevant to institutional talk in which participants conform to the rules governing the context. Drew and Heritage (1992) addressed how the participants' understanding of their institutional context might be evident in their talk and in the way they manage the conversation.

It is worth mentioning here that, although CA is used as a tool to identify patterns, it does not provide any theoretical information about the data or the contextual details therefore as it is social act. It does not treat language as an autonomous system independent of its use; instead, it treats grammar and lexical choices as sets of resources that participants deploy, monitor, interpret and manipulate in order to perform social actions (Schegloff et al., 2002,).

Finally, CA does not focus only on the verbal aspects of the interaction, such as turn taking, adjacency pairs, topic management and repair, but includes non-verbal aspects of the interaction, such as gazes and gestures.

\section{DATA COLLECTION}

The data were collected in a Saudi instructional setting in which English is used to teach various subjects such as chemistry, physics, early child education and information technology. The classes were chosen based on the teachers and on the students' willingness to be video 
recorded. The data consist of 16 hours of teaching sessions. The lessons were transcribed using Gail Jefferson's (2004) system of transcription (see Appendix 1).

According to Heritage and Atkinson (1984), the use of video and audio recording to collect and analyse data marks a significant shift in social science research. It is different from interviews in which the researchers treat the verbal accounts that the participants produce as "acceptable surrogates for the observation of actual behaviors" (Heritage \& Atkinson, 1984, p. 2). Heritage and Atkinson believed that the use of video recordings to collect data was also a departure from the experimental methods that are subject to researchers' manipulation and interference.

The use of video-recorded data makes the observations available for scrutiny for the sake of evaluation (Heritage \& Atkinson, 1984, p. 4; ten Have, 2007). Replaying the recordings of the data gives the researcher the opportunity to notice more details concerning interactions, and hence to increase the precision of the observations. It allows the researcher to reinvestigate the same data in the future in the light of paradigm shift and new findings.

\section{CHARACTERISTICS OF CONVERSATION ANALYSIS}

Conversation analysis, as researchers have argued, has, hypothetically, a set of interactional organisations that are believed to manifest in all kinds of interactions ranging from ordinary conversations to institutional interaction, from workplaces to on-line chat rooms, and which are common to different settings regardless of whether they are mundane or institutional. These features include turn taking, overlaps and interruptions, sequence organisation, adjacency pairs and preferences. Classrooms, as institutional settings, follow the same organisation of interaction in principle. However, classrooms have distinct features that make them unique in some aspects. The following section is meant to lay a foundation for understanding the subsequent analysis of interaction in CLIL classrooms. It aims to help to clarify the distinct interactional features of CLIL classrooms in comparison to other forms of mundane and institutional settings. The primary focus in the following section will be on six interactional organisations, namely turn taking, overlaps and interruptions, sequence organisation, adjacency pairs and preferences.

\section{Turn taking}

Turn taking is one of the most important aspects of CA mechanisms. Sacks et al. (1974, p. 696) described a model of turn taking as being "locally managed, party-administered, interactionally controlled and sensitive to recipient design". Hutchby and Wooffitt (2008, p. 49) discussed the mechanism of turn taking, adding that it consisted of two components: a 'turn-construction' component and a 'turn-distribution' component. Taking turns at talking can be seen as a process that consists of units, called turn-construction units (TCUs), which broadly correspond to linguistic categories such as sentences, clauses, single words or phrases. The TCUs enable the production and recognition of the transition-relevance places (TRPs) that indicate the first possible completion point of the current turn and the beginning of the next one as understood by the co-participants (Sacks et al., 1974, p. 703)

Sacks' early work in the late 1960s focused mainly on how people organise their talk, regardless of whether that talk is between two people or more. He stated that people are oriented to the 'only one speaker at a time' rule in conversation. However, in a dyadic conversation, he explained, people manage the turn-taking process via alteration, which requires a considerable amount of skill and continuous negotiation (Sacks, 1995, p. 130). 
Seedhouse (2004) summarised the set of rules that governs the actual process of turn allocation as follows:

- If the current speaker selects the next speaker in the current turn, then the current speaker must stop speaking and the next speaker must speak.

- If the current speaker does not select a next speaker, then any other participant may select himself or herself as the next speaker. The first person to speak at the TRP gains rights to the next turn.

- If the current speaker has not selected a next speaker, and if no other participant selfselects as in the second point, then the current speaker may (but need not) continue. The procedure then loops or recycles until the end of the conversation, for which there are of course further norms (Seedhouse, 2004, p. 28).

Nevertheless, because conversation does not usually proceed without some issues, the next section discusses such the types of problems that Sacks et al. (1974) referred to as overlaps and interruptions.

\section{Overlaps and Interruptions}

Overlaps, as Sacks et al. (1974, pp. 706-7) argued, are the result of “...competing self-selectors for a next turn, when each projects his start to be the earliest possible start at some possible transition relevance place (TRP), producing simultaneous starts". Levinson (1983, p. 299), on the other hand, stated that overlap takes place due to the misprojection of TRPs "for systematic reasons, e.g. where a tag or address term has been appended, in which case overlap will be predictably brief".

Interruption, on the other hand, was defined by West (1984, p. 55) as follows:

"An interruption is an initiation of simultaneous speech which intrudes deeply into the internal structure of a current speaker's utterance; operationally, it is found more than a syllable away from a possibly complete unit-type's boundaries".

\section{Sequence organisation, adjacency pairs and preferences}

Sequences are parts of the conversation that are longer than turns and are usually known as the main units through which the participants are able to make their utterances comprehensible and through which they interpret the utterances of others (Seedhouse, 2004, p. 21). Researchers also use sequences to investigate interaction in different settings due to their importance for the construction of meaning in a particular context. One of the most important examples of sequences organisation is adjacency pairs.

Schegloff and Sacks (1973, p. 238) defined adjacency pairs as pairs of sequences that are constructed out of related actions, such as when a participant produces the first part of a pair and the co-participant produces a related second part. However, this is not always a straightforward process, as there are cases in which the co-participant has alternative courses of actions according to which he/she reflects his orientation towards the first part of the pair. Schegloff (1968, p. 1083) stated that, once the first part of the pair has been produced, the second part becomes conditionally relevant. However, if the second part is not produced and is understood as being absent, this absence will be treated as noticeable, accountable and sanctionable (Seedhouse, 2004, p. 20). 
It is important to mention here that, even within simple and straightforward adjacency pairs such as offer-acceptance/refusal, the second part of the pair might be embedded, delayed, mitigated or withheld. Richards and Schmidt (1983, p. 129) discussed two types of adjacency pairs, distinguishing between those that were tightly constructed and those that allowed freedom. It is equally important to mention that, within the second part of the pair, there are "preferred" and "dispreferred" parts. These pairs are culturally sensitive. Levinson (1983, p. 334) compared these two types of second parts of pairs to the linguistic concept of markedness, whereby the preferred part represents the unmarked while the dispreferred represents the marked response.

\section{Repair}

Repair is an organised way of addressing problems in the interaction such as mishearing or misunderstanding (ten Have, 2007). Repair has different trajectories, types and sources. However, the most important factors characterising repair are who initiated it and who carried it out? Linguists emphasise the fact that any utterance is subject to repair. Repair has preference organizations that vary depending on the context. For instance, while otherinitiated repair and self-repair are the most preferred forms of repair, other-initiated repair and other-repaired are the least preferred. Schegloff et al. (1977) stated that self-correction is the most preferred type of correction. A limited context in which other correction is common is in adult-child conversation.

\section{Conversation analysis and institutional setting}

Ten Have (2007) argued that, although the idea of "institutional setting" was not recognised in Sack's work, his work is considered to be a good insight into the conversational devices and interactional formats that characterise non- institutional talk. It was not until the early 1980s that Heritage (1984, p. 290) introduced his dichotomy of CA in which he differentiated between research that focused on "the institution of interaction as an entity in its own right" and research that studies "the management of the social institution interaction". Since then, and according to CA participants, any speakers in any interaction, should be viewed as "knowledgeable social agents who actively display for one another their orientation to the relevance of context” (Hutchby \& Wooffitt, 2008, p. 139).

Drew and Heritage (1992) discussed the different types of institutional talk. They stated that each institutional setting has its own characteristics that work as a "fingerprint" that is "comprised of a set of interactional practices differentiating both from other institutional forms and from the baseline of mundane conversational interaction itself" (Drew \& Heritage 1992, p. 26)". Heritage (2003) argued that context is invoked and managed through interaction. Based on this definition of context, it became possible for researchers to investigate different institutional contexts by looking closely at the interaction taking place in them at the same time at which external constraints are considered to be influencing and determining factors regarding the type of behaviour that might be considered appropriate (Hutchby \& Wooffitt, 2008, p. 140).

\section{Classroom interaction in CLIL versus in EFL}

Despite the increasing number of studies that have examined classroom interaction in institutional settings, classroom interaction is still under-researched. Even the few studies that have addressed interaction in CLIL classrooms have done so using a pragmatic framework (Dalton-Puffer, 2005; Nikula, 2002; Dalton-Puffer \& Nikula, 2006; Morton, 2013). 
On the other hand, numerous studies have focused on classroom interaction in EFL and ESL classrooms (McHoul, 1978; Seedhouse, 2004; Walsh, 2002; Walsh, 2006; Sert, 2015). Seedhouse (2004), for instance, published a comprehensive study that examined the detailed interaction taking place in ESL classrooms. He presented a micro-analytical account of the interactional organisation in ESL classrooms. The study identified the fundamental relationship between the teacher's pedagogical focus and the resulting interaction in the classroom. Seedhouse (2004) identified four micro contexts in ESL. He described them as features of each ESL classroom, and listed them as form and accuracy, meaning and fluency, task orientation and procedural context.

Walsh (2011), on the other hand, identified four features of classroom interaction, namely control of the interaction, speech modification, elicitation and repair. He added that these features are not limited to ESL classes, but can be applied to any classroom. In this section, I will use the features that Walsh (2011) identified and will compare interactional features of ESL to those of CLIL as identified by other research frameworks, such as discourse pragmatics.

Table 1: Summary of EFL's versus CLIL's interactional features (Jawhar, 2012)

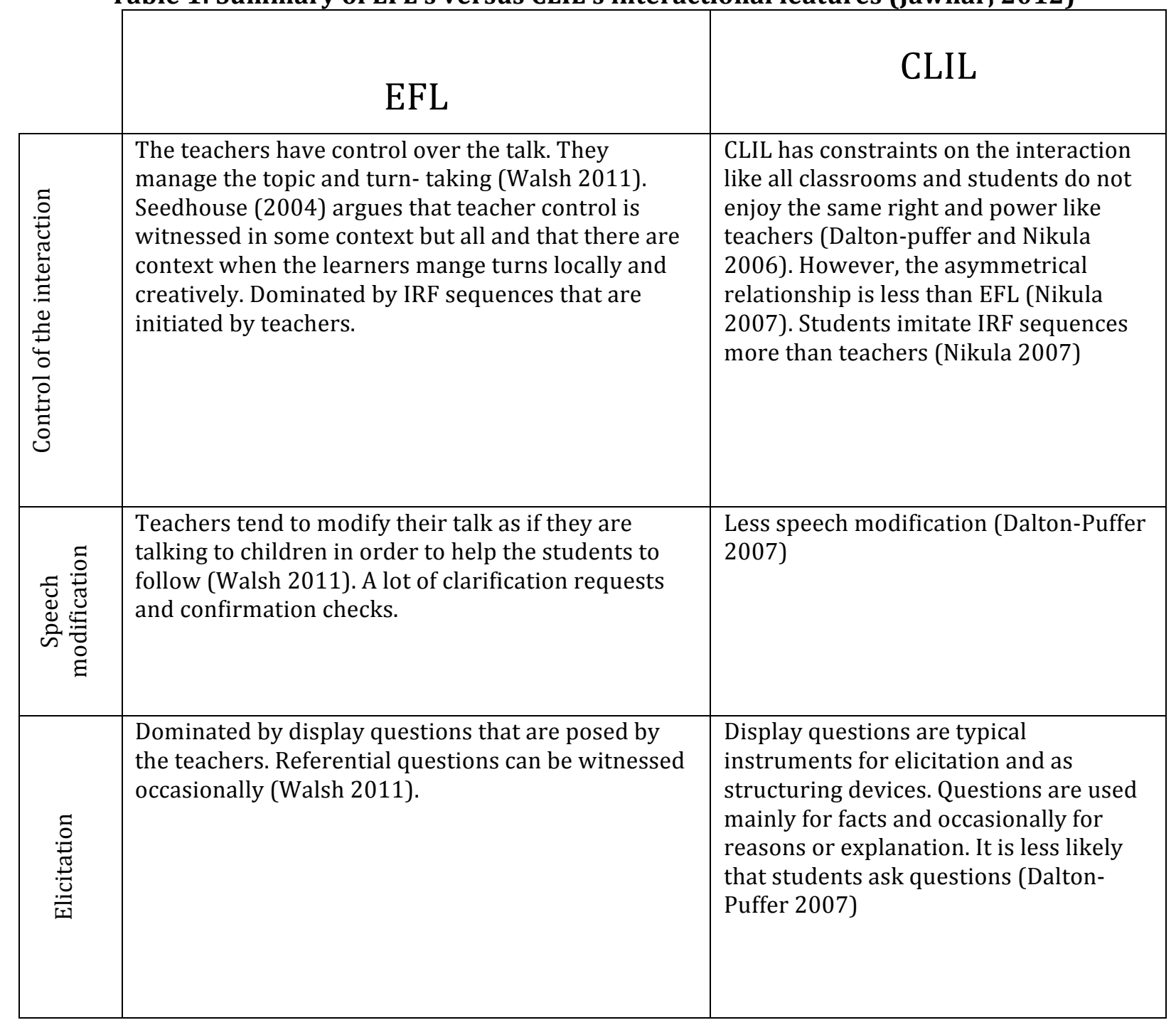




\begin{tabular}{|l|l|l|}
\hline & $\begin{array}{l}\text { Students expect their errors to be corrected (Walsh } \\
\text { 2011). Seedhouse (2004) argues that though there is } \\
\text { no single organization of repair in EFL, all learner } \\
\text { utterances are subject to evaluation. Repair targets } \\
\text { mainly the linguistic aspect of the communication. }\end{array}$ & $\begin{array}{l}\text { Repair varies depending on the type of } \\
\text { activity, i.e. teacher- or student- } \\
\text { centered. Repair is direct and with little } \\
\text { linguistic modification evidence. Mainly } \\
\text { focused on factual content errors. } \\
\text { Phonological and grammatical errors } \\
\text { receive the least repair (Dalton-Puffer } \\
\text { 2007) }\end{array}$ \\
\end{tabular}

\section{ANALYSIS OF CLASSROOM INTERACTION IN SAUDI CLIL CLASSES}

In this section, I will briefly describe the overall organisation of classroom interaction in Saudi higher education CLIL classrooms (hereafter SCLIL). The analysis is based on the turn-by-turn unfolding of the talk-in-interaction. SCLIL is examined as an institutional sitting (McHoul, 1978; Drew \& Heritage, 1992) in which the character of talk is explored in the light of the institution's goals. The institutional goals of CLIL in Saudi Arabia are to teach content subjects using English as a medium of instruction.

In the context in which this study is conducted, English is the only language that is used to teach science subjects. However, because acquiring English as an L2 is not the main focus of the programme, the linguistics properties of language are rarely discussed. Therefore, linguistic mistakes are not subject to evaluation in SCLIL and are largely ignored as long as they do not impede communication. In fact, factual or content-related mistakes are considered more important and are constantly subject to evaluation by the teachers, particularly when confusion in or breakdown of the interaction takes place. Sometimes, however, language is discussed when a given term is part of the teacher's pedagogical agenda. The following section presents an account of the most important classroom interactional features in Saudi CLIL classrooms using a detailed turn-by-turn micro analysis of the interaction as it unfolded.

\section{Turn taking}

Turn taking, as discussed in the previous section, can be defined as a mechanism whereby the participants construct their turns and control the distribution thereof while engaged in a social action. In this dataset, it has been noted that, unlike in L2 classrooms, the teacher rarely allocated turns in SCLIL classes. In fact, the students were able to nominate themselves and did not have to wait for the teacher to allocate turns. The teachers, on the other hand, nominated the students only when they noticed the students' inclination to participate, either by raising their hands or by establishing a mutual gaze with the teacher that is aimed at establishing reciprocity. In the majority of the cases, however, the students nominated themselves and took the floor as soon as the teachers reached what they perceived of as a possible TRP. Students sometimes attracted the teacher's attention to their desire to take the floor by using short response tokens during the teacher's turn in order to display their orientation to take the floor without interrupting he teacher's agenda or interrupting him or her. The next extract is taken from an IT classroom.

The teacher was talking to the students about a new technology, namely holograms. In lines 13 , the teacher introduces the new technology without naming it. S1 takes the floor in line 4 and asks the teacher to provide the name of this technology. The teacher responds in line 5 and the student checks her understanding by repeating the word "hologram" in what is understood by the teacher as a request for confirmation. He confirms the answer in line 7 and adds further 
information regarding the new technology. However, when the teacher tackles a culturally sensitive topic, namely "you can touch me",

the students laughed, which attracted the teacher's attention to what he had just said. Therefore, he self-repaired in line 13 and added "not that anybody can". In line 14, S1 used the short response "yes" to show agreement with the teacher's proposed position by displaying prior, shared knowledge of the topic, as proved by the way in which they construct their turns sequentially. In line $16, \mathrm{~S} 1$ added to the on-going discussion, saying "= we can through - we can walk through each other".

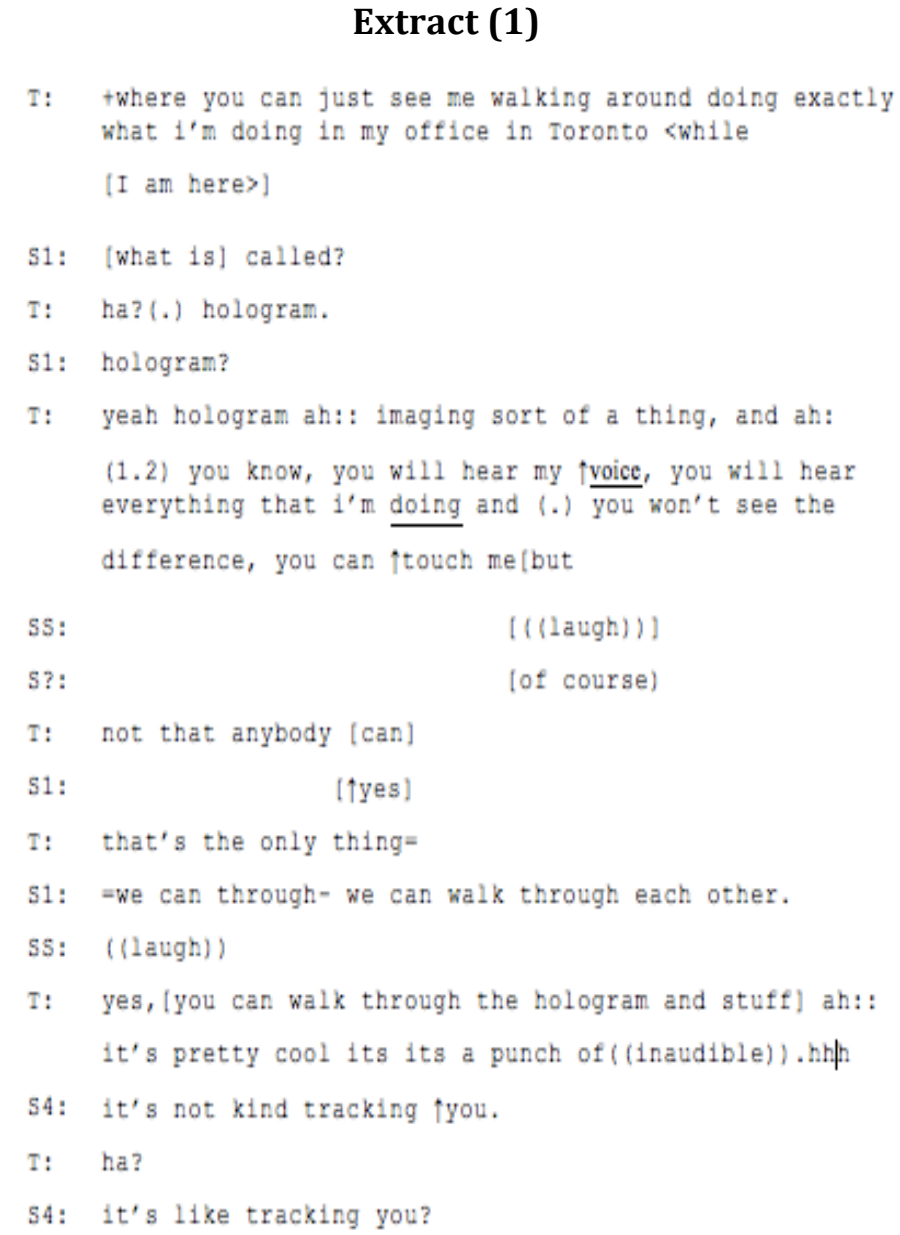

Once again, in line 17 the students laughed at what they perceived as a culturally sensitive yet humorous topic. The teacher projected other-initiated repair by reformulating the student's contribution in a more formal and less sensitive way "you can walk through the hologram" as opposed to walking through the teacher. In line 20, S4 also self-selected and added to the ongoing discussion using a graded assessment presented in a question format: "it's not kind tracking éyou". The teacher uses "ha" to express having difficulty in hearing or understanding the question. $\mathrm{S} 4$ rephrases her assessment slightly in line 22 by using rising intonation.

In this example, we have seen how the students felt they had sufficient liberty to take the floor each time they felt that they had something to add to the on-going talk. As mentioned earlier, they used short response tokens during the teacher's turn to show orientation towards participation. The next extract is taken from an IT class. The teacher is announcing that Google was sold or bided to be bought for two billion. In line 7, S1 did not indicate surprise by using 
any "newsmaker" devices such as "oh" or "really". In fact, she displayed having access to this information. Moreover, she added to the topic, saying "=yes, I think Microsoft."

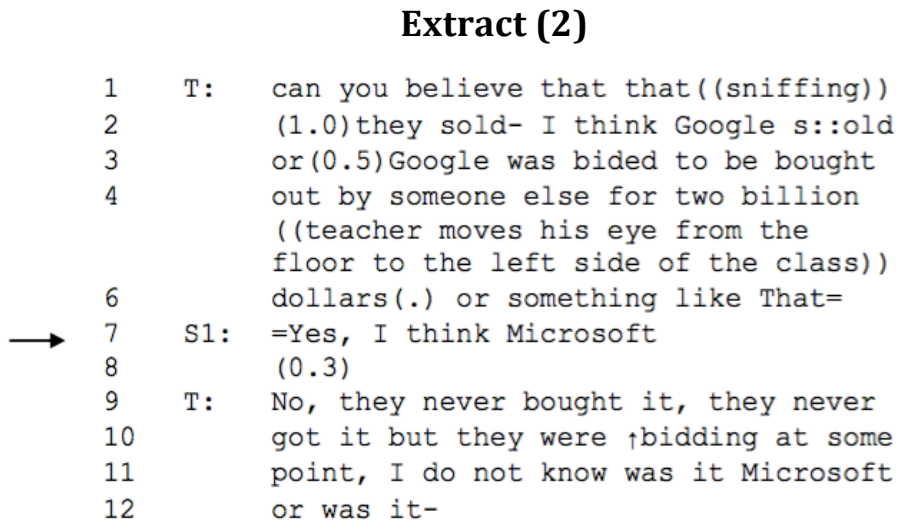

In this example, we see that the student waited until the teacher reached what she understood as a possible turn completion point to self-select, take the floor and add to the on-going conversation. The teacher did not seem to mind because he allowed the student to complete her turn and waited for 0.3 seconds to comment on what she had said, as can be seen in lines 912.

The teacher's selection of the students in this dataset is limited to only those moments at which the students showed readiness to participate. The following example is taken from a physics class. In this extract, the teacher is revising the questions that the students were given in a previous test as post-test feedback. In the middle of the teacher's explanation, S2 raises her hand in what is understood by the teacher as orientation to participation. The teacher looks in S2's direction and establishes eye contact with her, followed by saying "yes", which is understood by the student as permission to take the floor. The teacher terminated her turn and waited for a considerable period (2.3 seconds).

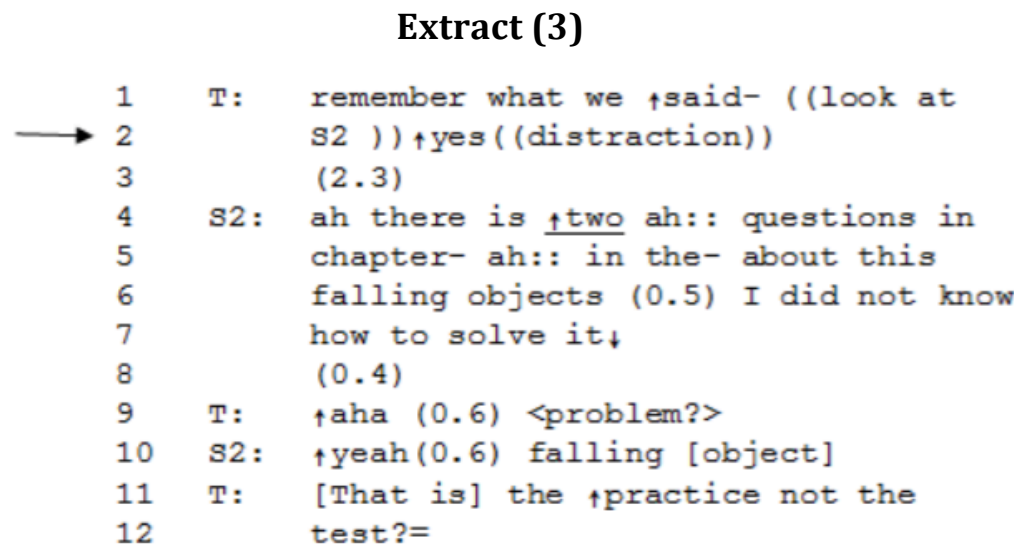

S2 takes the floor in lines 2-7 and asks a question about part of the chapter that she did not understand and thus could not solve. According to the teacher's next turn, this was not part of the teacher's pedagogical agenda at that time. However, the teacher displayed understanding of the source of the problem by using the acknowledgement device "aha" to express a change in her state of knowledge. The teacher (line 11) returned to her pedagogical agenda by stating that the question was related to practice and not to the test, which is what the teacher intended to address during the lesson. 


\section{Overlaps and interruptions}

In this dataset, we found that the students in the SCLIL class could easily take the floor and overlap with the teacher, sometimes managing the turn locally. This means that, despite the fact that the teachers did most of the talking, they were not completely immune from being interrupted by the students. Nevertheless, overlapping with the teacher was mainly observed when the students competed for the floor or when there was a tendency to "intensify the affiliative or disaffiliative nature of particular social actions" (Seedhouse 2004: p. 29). Overlapping also took place when the students wanted to ask questions related to the procedure. Giving up the floor by one of the participants and a restart by the other one usually solves the overlap problem.

The next example is taken from an early education classroom. The teacher had finished demonstrating the concept of modelling and asked if the students had any questions regarding what she had said. She asked the students to use green, orange and red cups to demonstrate their state of knowledge. For example, they used the green cups to indicate that they understood the material that had been introduced..

The teacher uses some Arabic to create humour and to express her desire to to be asked some questions. In lines 10-11, she asks the students a yes/no question that was aimed to further her pedagogical agenda. To her surprise, she experiences disagreement among the students. As some students said "yes" and others disagreed, the teacher had to put her pedagogical agenda aside and resolve the resulting overlap, as well as resolving the disagreement.

\section{Extract (4)}

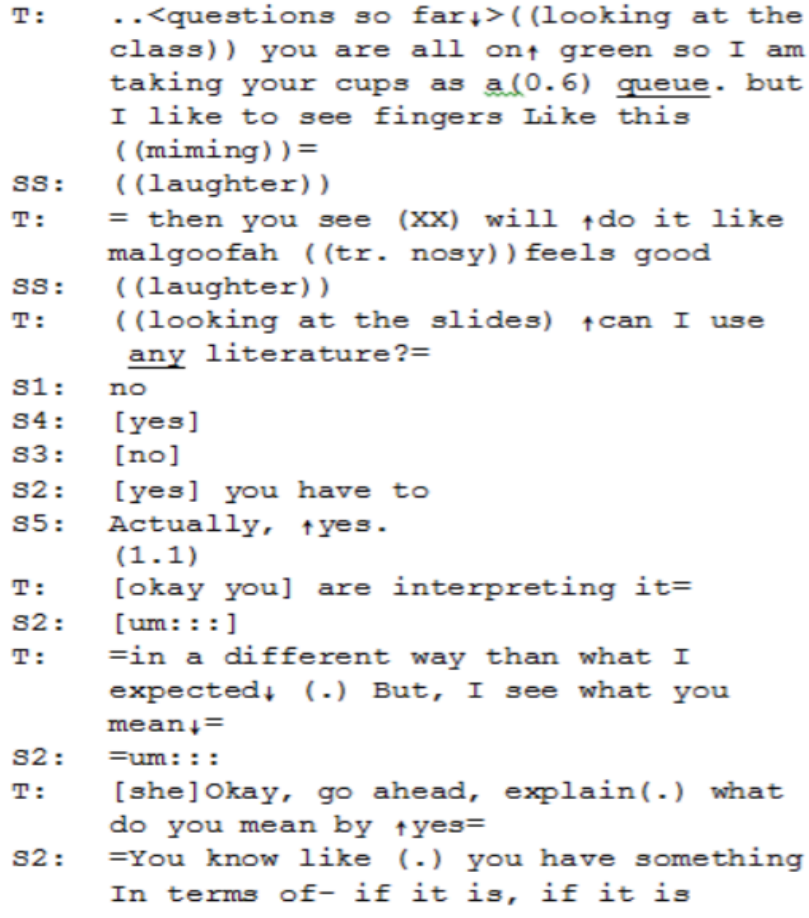

The teacher resolves the disagreement by telling the students that they had interpreted the issue in different ways (lines 18-25). S2 tries to take the floor twice during the teacher's turn by the use of the stretched sound "um:::::" The teacher finally notices her orientation, establishes a mutual gaze and gives her the floor (line 24) by using a turn that was prefaced by "okay" followed by a request for explanation. In this extract, we saw that disagreement 
resulted in the overlap of the students' turns, which was finally resolved by the teacher's clarification of the issue and selection of the next speaker.

The next example is taken from a physics class. The teacher is demonstrating a new example of solving problems regarding objects in motion. In line 10 , she decides to check the students' state of knowledge by asking direct questions regarding their understanding of what she has just explained.

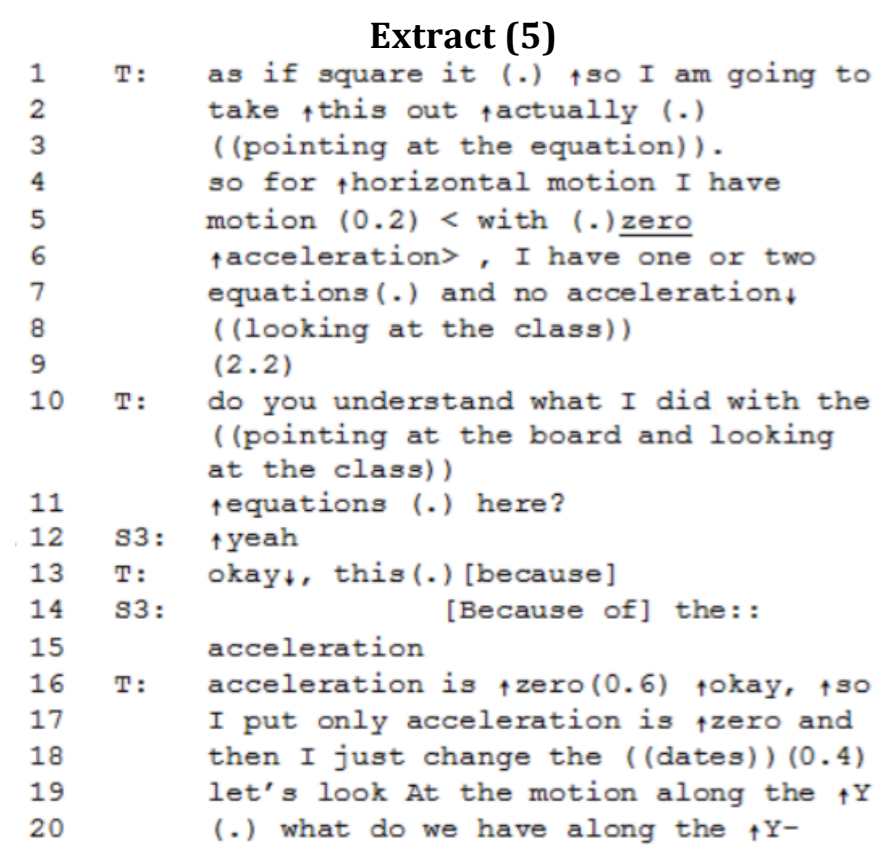

In line 12, S3 self-selects and answers the teacher's question with a single unit turn. The answer is perceived as unsatisfactory by the teacher, who responds using "okay" followed by further explanation. The student notices the teacher's dissatisfaction with her answer and interrupts the teacher's turn in line 14 in an attempt to provide further explanation as a complete to her initial answer. The teacher, however, ignores the student's attempt to elaborate and takes the floor in line 16, modelling the answer she was expecting from the students.

In this example, we notice that interruption is an extremely common phenomenon in SCLIL classrooms and that students do interrupt whenever they have something to add to the ongoing discussion.

\section{Topic management and development}

The teachers in SCLIL classes have very tight control of topic management. They introduce the topic, develop and manage it. The students, on the other hand, are not given much interactional space (Walsh, 2006) to express personal meaning or to develop topics on their own, particularly when the newly introduced topic conflicts with or does not suit the teachers' pedagogical agenda. When the students introduced a new topic that was not part of the discussion, the teachers claim their institutional authority and shifted the topic back to that which they perceived as appropriate to their moment-by-moment pedagogical agenda.

The following extract is taken from an early child education class. The teacher is explaining to the students the way that children tend to connect their own experiences in life with those of the characters to whom they are exposed in the stories that are read to them. The teacher (lines 1-8) gives examples of children connecting to the characters in a story they read, and 
then shifts the focus and asks the students about the possible age of the characters in a storybook for the fifth grade. Following a silence of 1.2 seconds, S3 self-selects and offers an answer.

\section{Extract (6)}

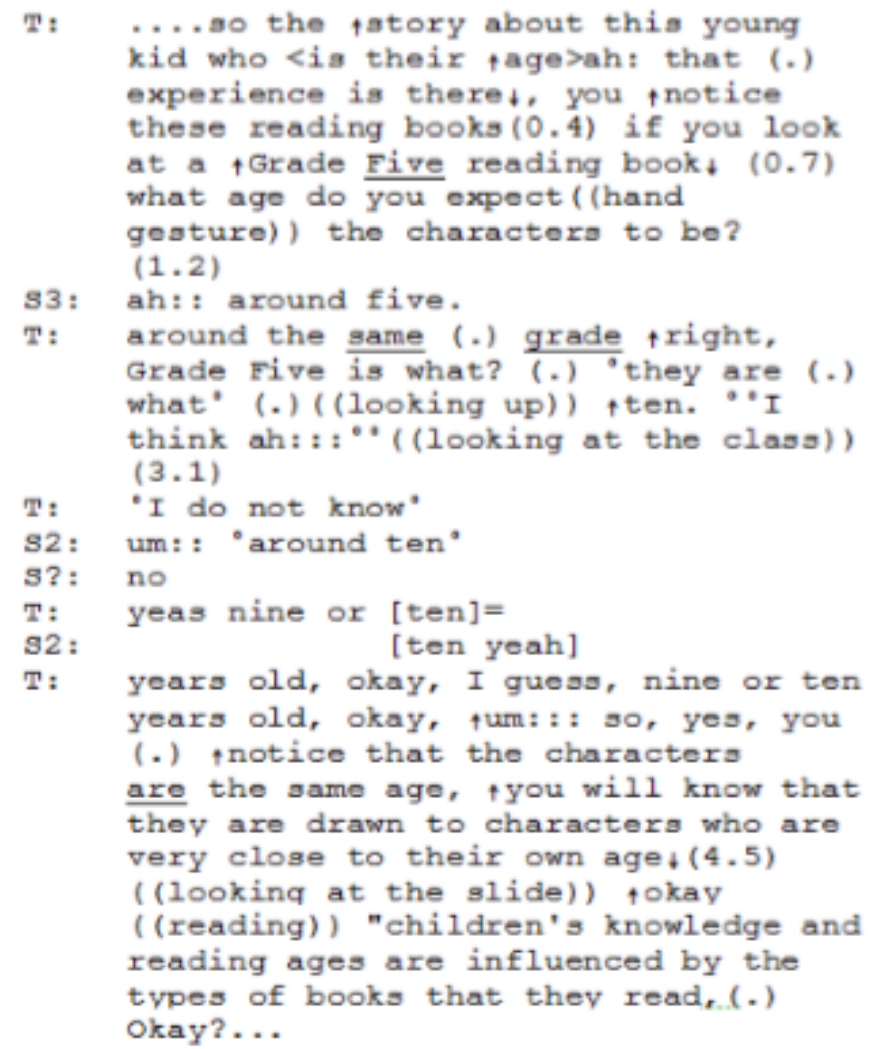

The teacher (lines 11-14) repeats the use of a series of questions that are not directed to anyone in particular in what seems to be a 'thinking aloud' technique, as understood from her following non-verbal action of "looking up". She follows this by guessing the age to be ten using a rising intonation that is followed by a gaze at the students in what is understood as a confirmation check. Following a considerable silence, (3.1 seconds), the teacher takes the turn again and claims a lack of knowledge. S2 self-selects (line 17) and gives the answer "around ten", but an unidentified student disagrees in line 18.

The next example is taken from a chemistry classroom. The students are doing a calculation task individually. 


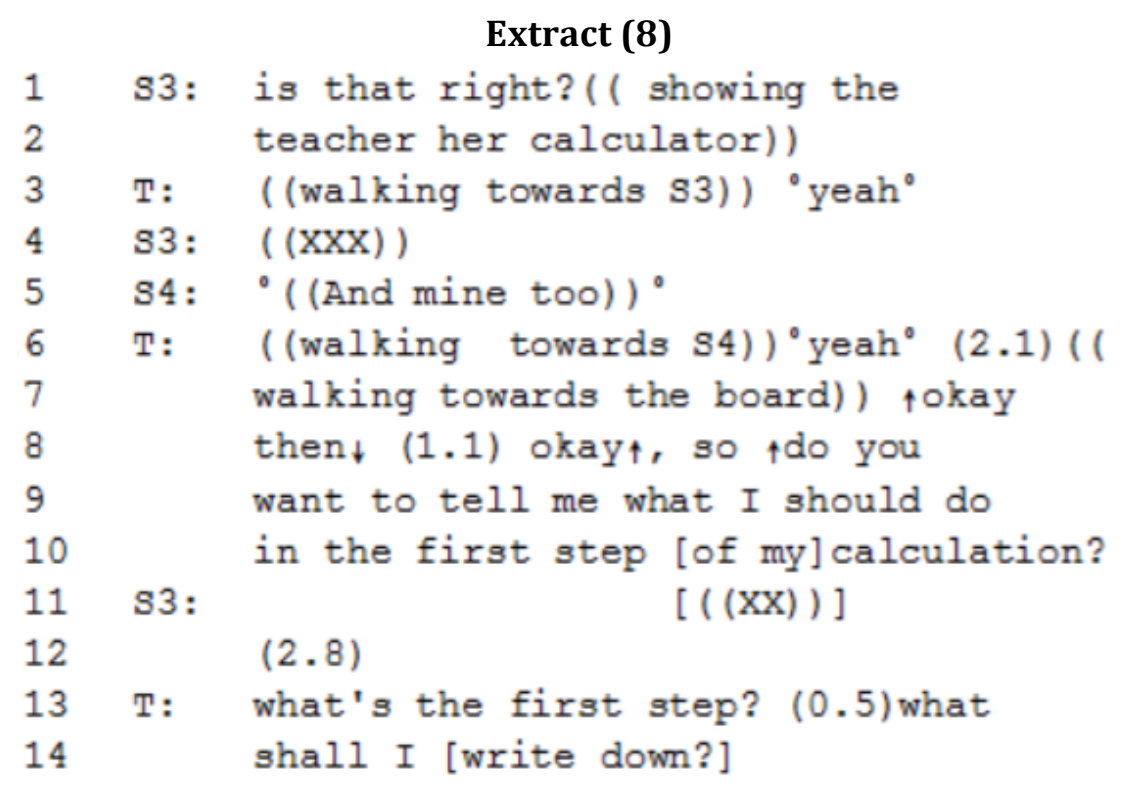

S3 holds her calculator up high in the air to attract the teacher's attention. She asks the teacher in private to check her answer. Because the question is specific and is asked in private, it receives a short, private answer. The same happens in line 5, when $\mathrm{S} 4$ also asks the teacher to check her answer and the teacher approves it using "yeah", followed by a series of discourse markers "okay, then, okay, so" to shift the activity from checking the students' answers individually to the next step of the lesson. Checking the students' answers individually could have wasted the teacher's time and interfered with her pedagogical agenda; thus, she exerts her institutional authority and shifts the topic to move her pedagogical agenda within the specific time she had planned.

From what has been mentioned previously, we can see how the students are oriented to the pre-allocated turn-taking system in SCLIL classes. We can also see that the students have the almost equal right to express personal opinions on the matter being discussed, but they do not the same amount of time to express their opinions as their teachers do, which causes them to tend to use shorter turns with fewer TCUs. Dalton-Puffer (2007) addressed this phenomenon inside CLIL classrooms under her discussion of "explanation". She attributed the short responses to the asymmetric distribution of knowledge that leads the students to assume that a simple, short utterance is sufficient "to serve as a trigger in order to activate the right kind of conceptual pattern in the teacher's mind" (Dalton-Puffer, p. 151). However, this paper used a step-by-step analysis to show that this phenomenon can also be attributed to the teachers' lack of emphasis on explicit verbal explanations by the students. The teachers tended to use few genuine wh-questions, which usually generate a more explicit verbalisation of knowledge.

\section{The organisation of repair}

Researchers consider repair as a core element in the learning process, particularly in L2 classrooms (Seedhouse, 2004; Markee, 2000). Therefore, it has been emphasised heavily. In CLIL classes, however, repair seems to be focused mainly on factual or content-related issues.

The majority of repair in this dataset took the form of other-initiated self-repair, as the teachers initiated the repair and ensured the students' uptake. Repair is carried out when breakdown in the interaction takes place in a way that affects the flow of the conversation, hence disturbing the pedagogical agenda. It usually takes the form of questions such as requests for clarification or confirmation checks, which makes the repair less threatening and 
factors such as loss of face are less likely. Direct overt repair is witnessed mainly among the learners themselves rather than the teachers correcting the students. When a learner initiates a less-preferred repair trajectory (other-initiated other-repair), it also targets the content rather than the linguistic form of her classmate. Seedhouse (2004) noticed a close relationship between repair and the teachers' pedagogical focus.

The following excerpt is taken from an ECED class. The teacher is discussing the importance of modelling or reading storybooks to children with the class.

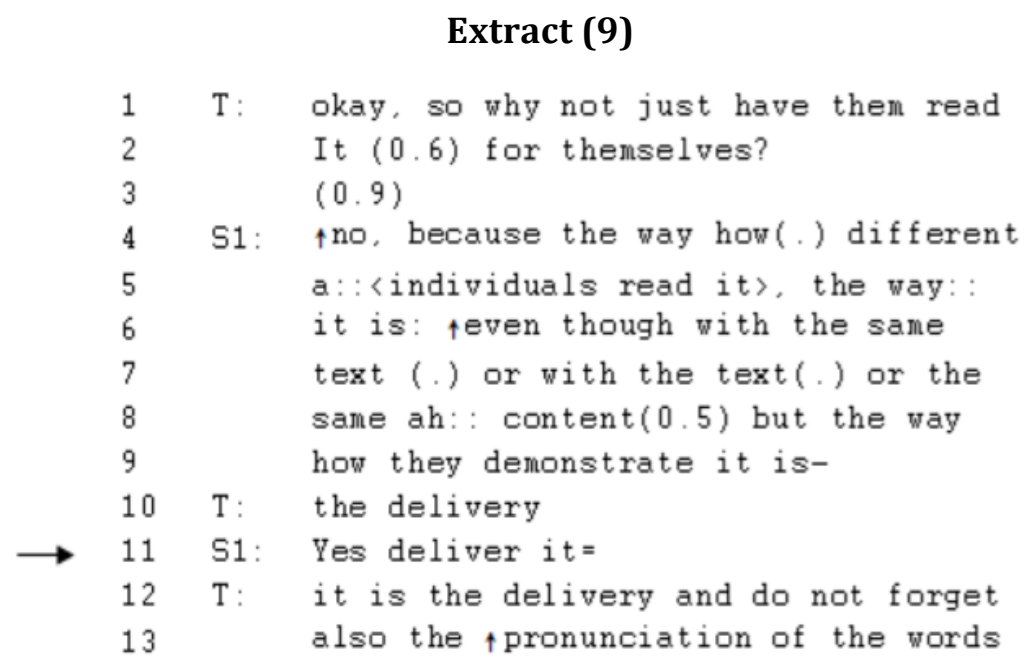

To elicit some answers and encourage participation, the teacher asks the students "why not just have them (children) read it (books) for themselves?" S1 disagrees with the proposition of the teacher's questions and starts her turn with the response token "no", followed by her account of the reasons that children should not read alone. However, the student's use of the verb "demonstrate" is not accepted by the teacher, who offers an other-initiated repair in line 10, "the delivery". The student, in line 11, agrees with the repair suggested by the teacher by using "yes" at the initial position of the TCU followed by a repetition of what she thinks is the suggested repair or the correct term. However, the teacher proves her wrong by offering a second overt repair, "it is the delivery", followed by a reminder of another important aspect of the repair, namely pronunciation. This is an example of repair that targets the language used, in this case the word choice, instead of the content. The only reason for this repair is that teaching terminology related to the specialty in the target language is crucial in this context.

The third example is taken from an IT classroom. The teacher is asking the students about the popularity of Google and the success thereof. 


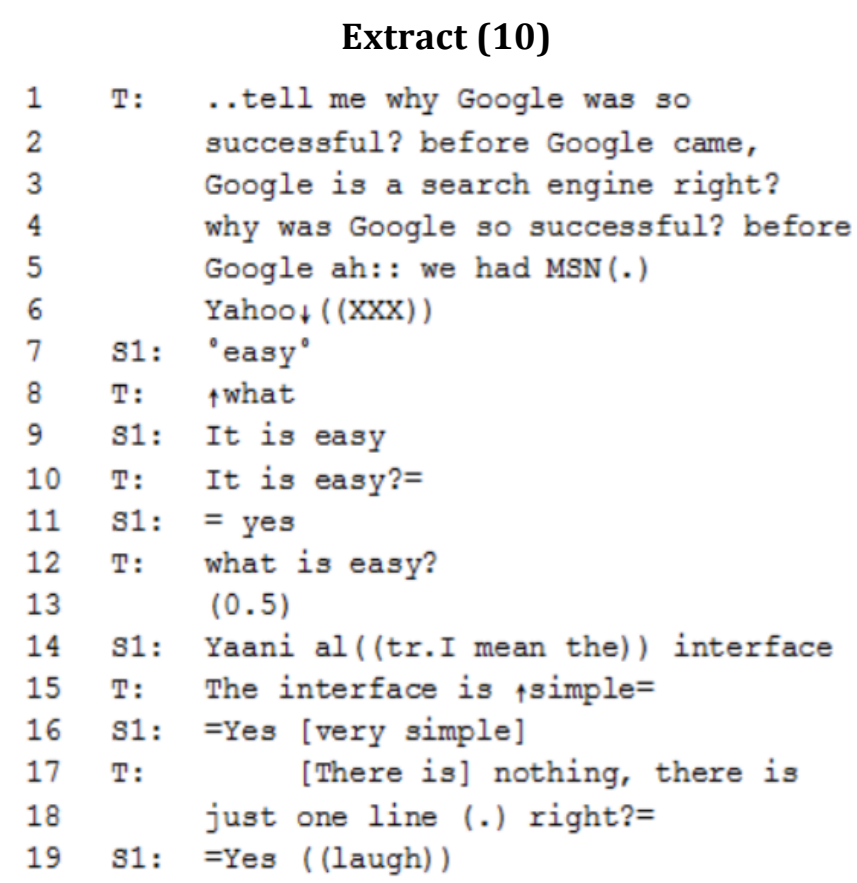

S1 self-selects and gives the minimum answer of a single unit turn using the adjective "easy". The teacher initiates open repair using "what". The use of "what" does not show whether the source of problem in the conversation mishearing or lack of understanding. The student responds (line 9) using "easy" in a complete sentence. However, using "easy" in a complete sentence does not solve the problem in the interaction, as can be understood from the teacher's response (line 10). The teacher then asks for further clarification using the student's prior turn at the initial position in what is understood as a confirmation check. The student responds positively in line 11 with "yes". However, the teacher indicates that the problem is in establishing intersubjectivity by explicitly asking, "what is easy?" The student modifies her answer in line 14 using the discourse marker "Yaani" from her L1 ((tr. I mean the)), followed by the further clarification, "interface". In line 15, the teacher initiates a repair using a reformulation of the sentence using the adjective "simple" in a confirmation check to offer the students the opportunity to self-repair in the next turn (Seedhouse, 2004). The student accepts by using "yes" and confirms her uptake of the repair by using the repaired item in her new turn. Once again, we notice that repair has become a necessity because of the breakdown in communication that resulted from the student's incorrect use of the target language's vocabulary, which affected the chances of establishing intersubjectivity among the participants.

\section{CONCLUSION}

In this paper, the researchers provided an account of Saudi higher education CLIL using the principles underpinning conversation analysis as their main method of analysis. By so doing, the researchers are contributing to the increasing amount of research that examines interaction in CLIL classes. They are also bridging an existing gap in the literature regarding the use of conversation analysis to study CLIL in general and Saudi CLIL in particular. Following a turn-by-turn analysis of the data, the authors have shed light on the reflexive relationship between CLIL teachers' pedagogical goals and classroom interaction (Seedhouse, 2004). This has been reflected clearly in those instances in which there was conflict caused by the students' contributions and the teachers' pedagogical focus. The finding is similar to that which Seedhouse (2004, pp. 184-5) presented regarding the existence of the same reflective relationship in L2 classroom interaction, where the interactants are "always displaying to one 
another their analyses of the current state of the evolving relationship between pedagogy and interaction and acting on the bases of these analyses" (Seedhouse, 2004., p. 185)".

With regard to the way on which epistemic knowledge is displayed or oriented, it is also been noted that, in this dataset, the teachers sometimes asked the students to display their epistemic stance of what was being discussed explicitly. The teachers often used the students' responses and built on them in order to move to the next step of the lesson or to shift the focus. The questions that the teachers asked were usually not designed to inform the teachers about something the students did not know or to test the students' knowledge. In fact, they were designed to allow the students display the knowledge they were supposed to have gained from the previous talk. In other words, the questions were designed to construct the social action of presenting the pedagogical agenda step by step. This was not done by asking only one question, but usually by the juxtaposition of all the questions in an entire lesson or in a section of a lesson (Dalton-Puffer, 2007). The students' questions, on the other hand, usually took the form of confirmation checks to shape their answers to the teachers' questions. Genuine questions were sometimes asked by the students, but were only related to the teachers' procedure.

To summarise, understanding the finer details of the interactional features of CLIL classes and comparing them to those of its counterpart, ESL/EFL classrooms, would have not been possible without the use of a method such as CA, which helped to paint a detailed picture of this complex context. Understanding these interactional features is expected to benefit researchers in the field of CLIL, as well as CLIL teachers who usually struggle with the use of a foreign language and the delivery of scientific knowledge, which requires tapping into higher-order thinking skills. However, because CA is not a method that can be used to generalize, this paper should be viewed as a window into CLIL that should be followed by similar work using a bigger corpus consisting of CLIL classrooms from all over the world. 


\section{APPENDIX}

\section{Transcription Conventions}

Adapted from Hutchby and Wooffitt (2008)

Numbers enclosed in parentheses indicate a pause. The number represents the number of seconds of duration of the pause, to one decimal place. A pause of less than 0.2 seconds is marked by (.)

[ ] Brackets around portions of utterances show that those portions overlap with a portion of another speaker's utterance.

An equal sign is used to show that there is no time lapse between the portions connected by the equal signs. This is used where a second speaker begins their utterance just at the moment when the first speaker finishes.

$:$ A colon after a vowel or a word is used to show that the sound is extended. The number of colons shows the length of the extension.

(hm, hh) These are onomatopoetic representations of the audible exhalation of air)

hh This indicates an audible inhalation of air, for example, as a gasp. The more h's, the longer the in-breath.

A question mark indicates that there is slightly rising intonation.

A period indicates that there is slightly falling intonation.

A comma indicates a continuation of tone.

A dash indicates an abrupt cut off, where the speaker stopped speaking suddenly. 

Up or down arrows are used to indicate that there is sharply rising or falling intonation. The arrow is placed just before the syllable in which the change in intonation occurs.

Under Underlines indicate speaker emphasis on the underlined portion of the word.

CAPS Capital letters indicate that the speaker spoke the capitalized portion of the utterance at a higher volume than the speaker's normal volume.

$$
\text { o }
$$$$
\begin{aligned}
& ><,<>\quad \text { 'Greater than' and 'less than' signs indicate that the talk they surround } \\
& \text { was noticeably faster, or slower than the surrounding talk. }
\end{aligned}
$$

(would) When a word appears in parentheses, it indicates that the transcriber has guessed as to what was said, because it was indecipherable on the tape. If the transcriber was unable to guess as to what was said, nothing appears within the parentheses.

marks the onset of a non-verbal action (e.g. shift of gaze, pointing)

italics English translation

\section{References}

Dalton-Puffer, C. (2005). Negotiating interpersonal meanings in naturalistic classroom dis- course: Directives in content and language integrated classrooms. Journal of Pragmatics, 37(8), 1275-1293.

Dalton-Puffer, C., \& Nikula, T. (2006). Pragmatics of content-based instruction: Teacher and student directives in Finnish and Austrian classrooms. Applied Linguistics, 27(2), 241- 267.

Drew, P. \& Heritage, J. (1992). Analyzing Talk at Work: An Introduction. In P. Drew \& J. Heritage, (eds.). Talk at work: Interaction in Institutional Settings (pp. 3-65). Cambridge: Cambridge University Press.

Firth, A. \& Wagner, J. (1997). On discourse, communication, and (some) fundamental concepts in SLA research. Modern Language Journal, 81(3), 285-300.

Jefferson, G. (2004). At first I thought' a normalizing device for extraordinary events. In. G. H. Lerner,(Ed.). Conversation Analysis: Studies from the first generation (pp.131-167). Philadelphia: John Benjamins. 
Hall, J.K. \& Verplaetse, L. (Eds.). (2000). Second and Foreign Language Learning through Classroom Interaction. Mahwah, New Jersey: Lawrence Erlbaum.

Heritage, J. (2003). 'Presenting Emanuel Schegloff.' In C. Prevignano \& P. Thibault (Eds.), Discussing Conversation Analysis: Emanuel Schegloff (pp.1-10). Amsterdam: Benjamins.

Heritage, J. (2004). Conversation analysis and institutional talk. In K. Fitch \& R. Sanders (eds.). Handbook of Language and Social Interaction (pp.103-147). Lawrence Erlbaum.

Heritage, J. (995). Conversation analysis: methodological aspects. In. U.M. Quasthoff (Ed.) Aspects of oral communication (pp.391-418). Berlin/New York: Walter de Gruyter.

Heritage, J. (1984). A change-of-state token and aspects of its sequential placement. In J. M. Atkinson \& J. Heritage (Eds.). Structures of Social action (pp.299-345). Cambridge, UK: Cambridge University Press, .

Heritage, J. \& Atkinson, J. M. (1984). Introduction. In. J. M. Atkinson \& J. Heritage (Eds.). The Structure of Social Action (pp.1-15). Cambridge, UK: Cambridge University Press.

Hutchby, I. \& Wooffitt, R. (1998). Conversation Analysis. Cambridge, UK: Polity Press

Hopper, R., Koch, S. \& Mandelbaum, J. (1986). Conversation analysis methods. In D. G. Ellis \& W. Donahue (Eds.). Contemporary issues in language and discourse (pp.169-187). Hillsdale, NJ: Lawrence Erlbaum.

Kasper, G. (1997). "A" Stands for Acquisition: A Response to Firth and Wagner. The Modern Language Journal, 81(iii), 307-312.

Levinson, Stephen C. (1983). Pragmatics. Cambridge University Press, Cambridge.

Liddicoat A. J. (1997). 'Interaction social structure and second language use: A response to Firth and Wagner'. The Modern Language Journal 81 (3) :313-317.

Markee, N., 2000. Conversation analysis. Mahwah, NJ: Erlbaum.

McHoul, A. (1978). The organization of turns at formal talk in the classroom. Language in Society, 7, $183-213$.

Morton, T. (2015). Vocabulary explanations in CLIL classrooms: a conversation analysis perspective . The Language Learning Journal, 43(3), 256-270.

Morton, T. (2012). Classroom talk, conceptual change and teacher reaction in bilingual science teaching. Teaching and Teacher Education, 28(1), 101-110.

Nikula, T. (2007). IRF pattern and space for interaction: Observations on EFL and CLIL classrooms. In C. DaltonPuffer \& U. Smith (Eds.). Empirical perspectives on CLIL classroom discourse (pp. 179-204). Frankfurt, Germany: Peter Lang.

Nikula, T. (2005). English as an object and tool of study in classrooms: Interactional effects and pragmatic implications. Language and Education, 16, 27-58.

Nikula, T. (2002). Teacher talk reflecting pragmatic awareness: A look at EFL and content-based classrooms. Pragmatics, 12(4), 447-468.

Pehkonen, M. (2008). Teachers' Evaluative turns in Finnish CLIL Classroom. Thesis. University of jyväskylä. Finland.

Pomerantz, A. \& Fehr, B. J. (1997). Conversation Analysis: An Approach to the Study of Social Action as Sense Making Practices. In. T. VanDijj (Ed.). Discourse as social interaction (64-91). London: Sage Publications.

Rampton, B. (1997). Language Crossing and the Redefinition of Reality: Implications for Research on Codeswitching Community (paper 5 in Working Papers in Urban Language \& Literacies). London: King's College.

Richards, J.C. \& Schmidt, R. (1983). Conversation Analysis. In J. C. Richards \& R., Schmidt (Eds.), Language and Communication (117-154). London, Longman.

Sacks, H. (1995). Lectures on conversation (Vol. 1). G. Jefferson (Ed.). Oxford, UK: Blackwell.

Sacks, H., Schegloff, E. \& Jefferson, G.(1974). A simplest systematics for the organization of turn taking for conversation. Language, 50(4), 696-735.

Seedhouse, P. (2004). The Interactional Architecture of the Language Classroom: A Conversation Analysis Perspective. Malden, MA: Blackwell 
Jawhar, S.S. \& Alnofaie, H.A. (2016). Mapping Interactional Organisation in CLIL Classrooms: Saudi Tertiary Level. Advances in Social Sciences Research Journal, 3(13) 241-260.

Sert , O. (2015). Social Interaction and L2 Classroom Discourse. Edinburgh: Edinburgh University Press. Schegloff, E. A. (1968). "Sequencing in Conversational Openings." American Anthropologist, 70: 1075-1095.

Schegloff, E.A., Koshik, I., Jacoby, S. \& Olsher, D. (2002). Conversation Analysis and Applied Linguistics. Annual Review of Applied Linguistics. 22, 3-31.

Schegloff, Emanuel A., Jefferson, Gail \& Sacks, Harvey (1977). The preference for self-correction in the organization of repair in conversation. Language, 53, 361- 382.

Shegloff, E. A. \& Sacks, H. (1973). Opening up closing. Semiotica, 8: 289-327. (reprinted in Baugh and Sherzer, 1984)

Ten Have, P. (2007). Doing conversation analysis: A practical guide. Thousand Oaks, CA: Sage.

Walsh, S. (2011). Exploring Classroom Discourse: Language in action. London /New York: Routledge.

Walsh, S. (2006). Investigating Classroom Discourse. London and New York: Routledge.

Walsh, S.(2002). Construction or Obstruction: teacher talk and learner involvement in the EFL classroom. Language Teaching Research, 6(1), 3-23.

West, C. (1984). When the doctor is a 'lady': Power, status and gender in physician-patient encounters. Symbolic Interaction, 7: 87-106 